\title{
ADVANTAGES AND DISADVANTAGES OF CHEMICAL METHODS IN THE ELABORATION OF NANOMATERIALS
}

\author{
Ecaterina Magdalena MODAN, Adriana Gabriela PLĂIAȘU \\ University of Pitesti, Romania \\ e-mail: ecaterina.modan@upit.ro, gabriela.plaiasu@upit.ro
}

\begin{abstract}
Reducing the size of macroscopic systems to nanometers can be achieved by top down synthesis by different chemical or physical methods. The bottom-up approach is a method in which the components of the atomic or molecular dimensions are assembled together to form nanoparticles. The bottom-up method is used for the elaboration of nanoparticles, because it allows the control of their size. This article presents a review of the advantages and disadvantages of chemical methods for the development of nanomaterials.
\end{abstract}

KEYWORDS: top-down, bottom-up, methods, elaboration, advantages, disadvantages

\section{Introduction}

The methods of synthesis of nanometric structures include two approaches, depending on the precursors used:

- top down

- bottom-up

In the first category, the "top down" synthesis, nanoparticles are obtained by reducing the size of macroscopic systems at nanometers. The reduction of the particle size can be achieved through different physical or chemical methods.
The methods of synthesis of "top down" are sought to be replaced or improved due to imperfections in the structure of the obtained material. This is a major limitation because the surface chemistry and other physical properties of the nanoparticles are strongly dependent on the structure of the material. In addition, they may contain significant amounts of impurities. The particles have a relatively wide distribution of different sizes and shapes.

Following the studies of the bibliographic references, the following advantages and disadvantages are presented in the Table 1.

Table 1. Advantages and disadvantages of "top down" synthesis

\begin{tabular}{|c|cc|}
\hline \multicolumn{1}{|c|}{ Advantages } & \multicolumn{2}{c|}{ Disadvantages } \\
\hline$\checkmark \quad$ large-scale production; & $\checkmark \quad$ size distribution (10-100 nm); \\
\hline$\checkmark \quad$ it is possible to deposit on a large \\
substrate; & $\checkmark$ & expensive technique; \\
\hline$\checkmark \quad$ no chemical purification is required. & $\checkmark$ & $\checkmark \quad$ various particle shapes; \\
\hline & $\checkmark \quad \begin{array}{c}\text { controlling the deposit parameters } \\
\text { is difficult to achieve. }\end{array}$ \\
\hline
\end{tabular}

The bottom-up approach is that method in which the components of atomic or molecular dimensions are assembled together to form nanoparticles. The bottom up method is much more used for the elaboration of nanoparticles, because it allows to control their size. The bottom up approaches have proved to be more versatile, which is why a multitude of nanoparticle synthesis techniques have been developed following the principle of self-assembly [1]. Following the studies of the bibliographic references, the following advantages and disadvantages are presented in the Table 2. 
Table 2. Advantages and disadvantages of "bottom up" synthesis

\begin{tabular}{|c|c|}
\hline Advantages & Disadvantages \\
\hline$\checkmark \quad$ obtained nanoparticles, nanotubes; & $\checkmark \quad$ large-scale production is difficult; \\
\hline$\checkmark$ the deposit parameters can be controlled; & $\begin{array}{c}\checkmark \quad \text { chemical purification of nanoparticles } \\
\text { is required. }\end{array}$ \\
\hline $\begin{array}{l}\checkmark \text { it is possible to distribute the narrow size } \\
(1-20 \mathrm{~nm}) \text {; }\end{array}$ & \\
\hline$\checkmark \quad$ cheaper technique. & \\
\hline
\end{tabular}

\section{Methods of elaboration}

\subsection{Sol-gel method}

The sol-gel method was first described by the chemist Ebelmen [2] in the mid-19th century. The soil is a colloidal suspension of oligomers ("oligomer = monomer molecular complex" whose diameter is several nanometers). Thereafter, this "soil" may be developed by chemical reactions, i.e. polycondensation or polyesterification, forming alcohol molecules in the bridges, until gel formation. This freezing process offers many advantages for producing large materials with homogeneity and purity at lower temperatures than conventional methods. Thus, the gel obtained is subjected to the drying process and the resulting product is transformed into xerogel, followed by a heat treatment that will eventually form powders [3, 4].

The sol-gel method does not involve melting or sintering powders to produce ceramics, but uses a solution containing reactive precursors such as alkoxides or metal salts. The precursors for the preparation of a colloid consist of a metal or metalloid element surrounded by various ligands. Metal alkoxides (R-O-M) are similar to alcohols (R$\mathrm{OH}$ ) with a metal atom $\mathrm{M}$, replacing hydrogen $\mathrm{H}$ in the hydroxyl group. They are the class of chemical precursors most commonly used in soil-gel synthesis, because they are subject to hydrolysis depending on the amount of water and the catalyst present.

The sol-gel method makes it possible to obtain various materials, especially in the form of films, fibers, monoliths or submicron powders.

The sol-gel technique is based on two classic chemical reactions of nucleophilic substitutions: hydrolysis and condensation according to the following: reaction:

The hydrolysis is reproduced by the following

$$
\mathrm{M}-\mathrm{OR}+\mathrm{H}_{2} \mathrm{O}=\mathrm{M}-\mathrm{OH}+\mathrm{ROH},
$$
below:

The condensation is given by the reactions

$$
\mathrm{M}-\mathrm{OR}+\mathrm{HO}-\mathrm{M}=\mathrm{M}-\mathrm{O}-\mathrm{M}+\mathrm{R}-\mathrm{OH}
$$

$\mathrm{M}-\mathrm{OH}+\mathrm{HO}-\mathrm{M}=\mathrm{M}-\mathrm{O}-\mathrm{M}+\mathrm{HO}-\mathrm{H}$

where: $\mathrm{M}$ represents a metal cation such as silicon, titanium or zirconium and the organic $\mathrm{R}$ alkyl group.

Researchers have become aware of the potential of the sol-gel method to provide new advanced functional materials, based on various micro and macrostructures. Thus, Shek et al. (1999) obtained by the sol-gel method of tin oxide, $\mathrm{SnO}_{2}$ nanocrystals with a particle size close to $3.5 \mathrm{~nm}$ [5].

Piccaluga et al. (2000), Huang et al. (2003) made composite nanopowders containing elementary nano- $\mathrm{Ni}-\mathrm{SiO}_{2}$ and $\mathrm{Fe}-\mathrm{Al}_{2} \mathrm{O}_{3}$ particles. Bruni and his colleagues (1999) synthesized the following oxides using this method: $\mathrm{Fe}_{2} \mathrm{O}_{3}-\mathrm{SiO}_{2}, \mathrm{NiO}-\mathrm{SiO}_{2}$ or $3 \mathrm{Al}_{2} \mathrm{O}_{3}-$ $2 \mathrm{SiO}_{2}$, thus verifying that the sol-gel technique is a good way to produce nanocomposites containing inorganic nanoparticles [6]. Andrei Jitianu and his collaborators have developed nano-sized $\mathrm{SnO}_{2}$ clusters using sol-gel technique [7]. S. Mahshid and his team synthesized $\mathrm{TiO}_{2}$ powders by this method [8]. In the 2001 paper, Gash and his colleagues developed nanostructured iron oxide (III) monolith $\left(\mathrm{Fe}_{2} \mathrm{O}_{3}\right)$ by the sol-gel synthesis method with the iron chloride (III) reagent [9]. Research continued later and Tang and colleagues (2004) synthesized thin magnetite films $\left(\mathrm{Fe}_{3} \mathrm{O}_{4}\right)$ using the same procedures and reagents, but found that pure magnetite could not be synthesized by using iron (III) chloride as a precursor due to the formation of impurities of hematite $\left(\alpha-\mathrm{Fe}_{2} \mathrm{O}_{3}\right)$ and magnetite $\left(\gamma-\mathrm{Fe}_{2} \mathrm{O}_{3}\right)$ [10]. In 2013 Shaker and his colleagues obtained sol gel magnetic nanoparticles $\left(\mathrm{Fe}_{3} \mathrm{O}_{4}\right)$ technique and showed that the crystallinity was improved at a higher treatment temperature and therefore the particle agglomeration decreased dramatically [11]. Khodadadi and his colleagues developed sol-gel method of $\mathrm{Al}_{2} \mathrm{O}_{3}$ nanocrystals and Fe-doped $\mathrm{Al}_{2} \mathrm{O}_{3}$ nanocrystals [12]. Sun and his associates successfully reported soluble gel-soluble $\mathrm{ZnO}$ thin films at a relatively low temperature $\left(\leq 200{ }^{\circ} \mathrm{C}\right)$, which can function as an efficient transport layer in inverted solar cells [13]. Copper oxide nanostructures were synthesized by this method using different concentrations of copper nitrate [14]. Research conducted by Tayseir. M., and his collaborators in 2017 led to the sol-gel synthesis of hydrophobic 
silicon nanoparticles containing zirconium, highlighting the influence of zirconium content on the texture, structure and morphology of the synthesized silica [15]. Following the studies of the bibliographic references, the following advantages and disadvantages of this process are presented, presented in Table 3.

Table 3. Advantages and disadvantages of the sol-gel method

\begin{tabular}{|c|c|}
\hline Advantages & Disadvantages \\
\hline $\begin{array}{c}\checkmark \quad \text { can produce a thin coating to ensure } \\
\text { excellent adhesion between the substrate } \\
\text { and the top layer; }\end{array}$ & $\begin{array}{c}\checkmark \quad \text { the contraction that occurs } \\
\text { during processing; }\end{array}$ \\
\hline $\begin{array}{c}\quad \text { can produce a thick coating to provide } \\
\text { protection against corrosion; }\end{array}$ & $\begin{array}{c}\checkmark \quad \text { residual hydroxyl and / or } \\
\text { carbon groups; }\end{array}$ \\
\hline $\begin{array}{l}\checkmark \quad \text { it has the capacity of sintering at low } \\
\text { temperatures, between } 200-600^{\circ} \mathrm{C} \text {; }\end{array}$ & $\checkmark \quad$ long processing time; \\
\hline $\begin{array}{c}\quad \text { simple, economical and efficient method } \\
\text { to produce high quality coverage; }\end{array}$ & $\checkmark \quad$ fine pores; \\
\hline $\begin{array}{c}\text { synthesizes high purity products, because } \\
\text { the organo-metallic precursor of ceramic } \\
\text { oxides can be dissolved in a specified } \\
\text { solvent and hydrolyzed in a soil and } \\
\text { subsequently a gel, the composition can } \\
\text { be highly controllable. }\end{array}$ & $\begin{array}{c}\checkmark \quad \text { use of organic solutions that } \\
\text { can be toxic. }\end{array}$ \\
\hline
\end{tabular}

\subsection{Polymer precursor method (PPM) - Pechini method}

The method was proposed in 1967 as a technique for depositing titanium and niobium dielectric films and alkaline-earth metals in condensation production. Later, the process was customized for the synthesis of oxide materials in the laboratory.

Table 4. Advantages and disadvantages of the Pechini method

\begin{tabular}{|c|c|}
\hline Advantages & Disadvantages \\
\hline$\checkmark \quad$ versatility; & $\checkmark \quad$ use of toxic ethylene glycol and organic \\
reagents;
\end{tabular}

The method is based on an intense mixing of the positive ions in a solution, the controlled transformation of the solution into a polymeric gel, the removal of the polymeric matrix and the development of an oxide precursor with a high degree of homogeneity [16]. During the synthesis process, metal salts or alkoxides are introduced into a solution of citric acid with ethylene glycol. The formation of citric complexes balances the difference in the individual behaviour of the ions in the solution, which leads to a better ion distribution and prevents the separation of the components in the later stages of the process. Polycondensation of ethylene glycol and citric acid begins at over $100{ }^{\circ} \mathrm{C}$, resulting in the formation of citrate polymer [17]. When the heating temperature exceeds $400{ }^{\circ} \mathrm{C}$, oxidation and pyrolysis of the polymeric matrix begins, which results in the formation of an amorphous oxide and a carbonate precursor. Subsequent heating of this precursor results in the formation of the required material with a high degree of homogeneity and dispersion. Today, the Beijing method is widely used in the synthesis of dielectric, fluorescent and magnetic materials, 
superconductors and high temperature catalysts, as well as for oxide films and coatings [18, 19].

Following the studies of the bibliographic references, the following advantages and disadvantages of the polymeric precursors' method presented in Table 4.

\subsection{Microemulsion method}

Microemulsions are isotropic solutions, macroscopically homogeneous and thermodynamically stable, containing at least three components, namely a polar phase (usually water), a nonpolar phase (usually oil) and a surfactant. At the microscopic level, the surfactant molecules form an interphase film that separates the polar and nonpolar domains. This interface layer forms different microstructures, ranging from oil droplets dispersed in a continuous aqueous phase (oil / water microemulsion) to a bicontinuous phase with water droplets dispersed in a continuous oil phase (water / oil microemulsion).

The latter can be used as nanoreactors for the synthesis of low polydispersion nanoparticles (Julian et al. 2006, Destree et al. 2008, Zhong-Min et al. 2007, Wanzhong et al. 2006) [20-23].

Different types of microemulsions are known, such as water in oil (A/U), oil in water (U/A), water in $\mathrm{sc}-\mathrm{CO}_{2}\left(\mathrm{~A} / \mathrm{sc}-\mathrm{CO}_{2}\right)$, oil in $\left.\mathrm{sc}-\mathrm{CO}_{2} \mathrm{U} / \mathrm{sc}-\mathrm{CO}_{2}\right)$. The microemulsion method is one of the versatile preparation techniques that allows the control of the properties of particles such as size, geometry, morphology, homogeneity and surface area (Hu et al., 2009, Pileni, 2003) [24, 25].

Many published studies discuss different aspects of microemulsions (Pileni, 2001, Pileni, 2007, Pileni, 2008, Lopez-Quintela and co-workers, 2004, Cushing and co-workers, 2004, Shervani and co-workers, 2003) [26-31].

The microemulsion method was used for the synthesis of colloidal compounds, as follows: colloidal $\mathrm{Fe}_{3} \mathrm{O}_{4}$, colloidal $\mathrm{AgCl}$, nanocrystalline $\mathrm{Fe}_{2} \mathrm{O}_{3}, \mathrm{TiO}_{2}, \mathrm{Al}_{2} \mathrm{O}_{3}$ and $\mathrm{YBa}_{2} \mathrm{Cu}_{3} \mathrm{O}_{7}$ (Boutonnet and co., 1982, Ayyup and co., 1988, Hou and Shah, 1988, Lal and co. his, 1998, Zhang et al., 2002) [32-39].

The term microemulsion was proposed by Schulman et al. (1959). They prepared a quaternary solution of water, benzene, hexanol and K-oleate, which was stable, homogeneous and slightly opalescent. These systems became clear as soon as a short-chain alcohol was added. In 1943-1965, Schulman and his colleagues described how to prepare these transparent systems. Basically, a coarse (or macro) emulsion was prepared and the system was then titrated to form a transparent solution by the addition of a co-surfactant (the second surfactant). Most of the work reported by Schulman concerned systems with four components: hydrocarbons (aliphatic or aromatic), ionic surfactants, cosurfactants (generally carbon chain 4-8 aliphatic alcohol) and an aqueous phase [40]. He proposed that the surfactant and co-surfactant, when properly selected, form a mixed film at the oil / water interface, resulting in an interphase pressure that exceeds the initial positive interfacial tension. To summarize, the basic observation made by Schulman et al. was that when a co-surfactant is titrated in a coarse compound microemulsion from a mixture of water / surfactant in an amount sufficient to obtain micro-droplets, the result can be a system that is low viscosity, transparent, isotropic and very stable. The titration from the opaque emulsion to the transparent solution is spontaneous and well defined. It has been found that these systems are made of spherical microdroplets with a diameter between $600 \mathrm{~nm}$ and 800 nm. It was not until 1959 that Schulman proposed to name microemulsions of these systems. Previously, he used terms such as transparent water and oil dispersion, oleopathic hydromicels or hydropathic oleomycetes. From this moment, microemulsions have found a wide range of applications, from oil recovery to nanoparticle synthesis, as reported by Chhabra et al. (1997) [41].

The advantages and disadvantages of the microemulsion method are summarized in the following Table 5 .

Table 5. Advantages and disadvantages of the microemulsion method

\begin{tabular}{|c|c|}
\hline Advantages & Disadvantages \\
\hline $\begin{array}{c}\checkmark \quad \text { they are easy to prepare and do not } \\
\text { require an energy contribution during } \\
\text { synthesis; }\end{array}$ & $\checkmark \quad$ large amount of surfactants; \\
\hline $\begin{array}{c}\checkmark \quad \text { the preparation is due to better } \\
\text { thermodynamic stability; }\end{array}$ & $\begin{array}{c}\checkmark \quad \text { temperature stability influenced by } \\
\text { microemulsion, } \mathrm{pH} ;\end{array}$ \\
\hline $\begin{array}{c}\checkmark \quad \text { the formation of the microemulsion is } \\
\text { reversible; }\end{array}$ & $\begin{array}{c}\checkmark \quad \text { limited solubility capacity for substances } \\
\text { with high melting points. }\end{array}$ \\
\hline$\checkmark \quad$ thermodynamically stable; & \\
\hline$\checkmark \quad$ low viscosity compared to emulsions. & \\
\hline
\end{tabular}




\subsection{Hydrothermal method}

The hydrothermal method consists of obtaining nanomaterials through hydrolysis reactions at high temperatures of the various compounds directly in an autoclave. The synthesis can have as precursors products obtained previously at room temperature based on the crystallization of the phases under high temperatures and pressures. Hydrothermal synthesis can be performed both at temperatures and at pressures below the critical point for a specific solvent over which the differences between liquid and vapor disappear and under supercritical conditions. The solubility of many oxides in hydrothermal salt solutions is much higher than in pure water (such salts are called mineralizers). There is also a group of solvothermal synthesis methods, related to hydrothermal methods; this group of methods is based on the use of organic solvents and supercritical $\mathrm{CO}_{2}$ [42]. Substantial improvement of the hydrothermal method facilitates the use of additional external factors to control the reaction environment during the synthesis process. From now on, this approach is implemented in the methods of microthermal hydrothermal synthesis, hydrothermalultrasonic, hydrothermal-electrochemical and hydrothermal-mechanochemical. The hydrothermal method is a simple and versatile method for the synthesis of inorganic nanomaterials at high temperatures and pressures. Thus, it is possible to obtain the nanoparticles by adjusting the processing conditions, including temperature, pressure or concentration of precursors. The main parameters of the hydrothermal synthesis, which define both the process kinetics and the properties of the resulting products are the initial $\mathrm{pH}$ of the solution, the duration, the temperature of the synthesis and the pressure in the system [43]. The synthesis is carried out in autoclaves that are stainless steel cylinders, which can withstand high temperatures and pressures for a long time. A precursor solution, often in the presence of a hydrolysis agent, is autoclaved at a certain temperature for a certain period of time. In a typical hydrothermal process, the aqueous solution of the precursor and $\mathrm{KOH}$ is mixed and introduced into the autoclave maintained at $70-200{ }^{\circ} \mathrm{C}$ for $10-24$ hours depending on the process and then cooled in air at room temperature. The resulting precipitate is collected by filtration, washed and finally dried. For example, nickel ferrite particles prepared by hydrothermal processes led to size distribution particles from 40-90 nm, as reported by Cheng et al. [37], according to the reaction:

$$
\mathrm{NiCl}_{2} \cdot 6 \mathrm{H}_{2} \mathrm{O}+\mathrm{Fe}\left(\mathrm{NO}_{3}\right)_{3} \cdot 9 \mathrm{H}_{2} \mathrm{O}+\mathrm{KOH}(\mathrm{aq})=\mathrm{NiFe}_{2} \mathrm{O}_{4}
$$

Some of the most popular nanomaterials produced by the hydrothermal method are synthetic zeolites. A prerequisite for their production is the presence in solution of surface agents (SAAs) that actively influence the morphological evolution of oxide compounds in hydrothermal solutions. The choice of the synthesis conditions and the type of surfactants can ensure the production of targeted pore nanomaterials with a pore size, controlled in a wide range of values [44]. The advantages and disadvantages of the hydrothermal method are summarized in the following Table 6.

Table 6. Advantages and disadvantages of the hydrothermal method

\begin{tabular}{|c|c|}
\hline Advantages & Disadvantages \\
\hline $\begin{array}{c}\checkmark \quad \text { the ability to synthesize substances that are } \\
\text { unstable near the melting point; }\end{array}$ & $\checkmark$ high cost of equipment; \\
\hline $\begin{array}{c}\checkmark \text { the ability to synthesize large crystals of high } \\
\text { quality. }\end{array}$ & \\
\hline
\end{tabular}

\subsection{Sonochemical method}

The sonochemical method is one of the recently discovered techniques that offers a versatile way to obtain nanostructures for different applications. This represents the use of high intensity ultrasounds, which induce synthesis conditions distinct from other conventional methods such as hydrothermal synthesis, spray pyrolysis method and wet chemical method (Bang and Suslick, 2010; Suslick, 1990; Suslick and Price, 1999).

These specific conditions are generated during acoustic cavitation, which produce high temperatures and high pressures in the center of the bubbles formed in the solution. The bubbles are obtained when the solutions are exposed to high intensity ultrasound. The reaction conditions in the sonochemical method are as follows:

- the speed of noise in the liquid should be in the range $1000-1500 \mathrm{~ms}^{-1}$;

- the ultrasonic wavelength is required between $10 \mathrm{~cm}$ and $100 \mu \mathrm{m}$;

- the frequency range from $20 \mathrm{kHz}$ to $15 \mathrm{MHz}$ is required.

Suslick in his 1989 paper points out that cavitation is the formation, growth and implosive bursting of bubbles in a liquid. Cavitation collapse produces intense local heating ( $5000 \mathrm{~K})$, high 
pressures ( $1000 \mathrm{~atm})$ and enormous heating and cooling speeds $(>109 \mathrm{~K} / \mathrm{sec})$ and fluid jet flows ( $400 \mathrm{~km} / \mathrm{h}$ ) [39].

Two types of materials, such as volatile and non-volatile precursors, have been used in the sonochemical method as a raw material for the production of nanomaterials through different reaction mechanisms (Xu et al.) [45].

If volatile compounds are used as precursors in the sonochemical method, it is called primary sonochemistry, and if non-volatile compounds are used, it is called secondary sonochemistry.

In primary sonochemistry, free metal atoms are generated from volatile organometallic compounds by bond dissociation, facilitated by the high temperature produced during bubble collapse. The obtained atoms are injected into the liquid phase and subsequent nucleation gives rise to nanoparticles of various materials in the presence of a suitable template. In the latter case, the sonochemical reactions occur just outside the balloon, which is subjected to the reaction with the radicals. Radicals diffuse into the liquid, result in a reaction and generate nanomaterials.

Using this method, different metal oxide nanoparticles have been developed, and the number of papers that report data on their synthesis and application is quite large. Among the metal oxides, the synthesis and applications of the transition metal oxides, and in particular $\mathrm{TiO}_{2}, \mathrm{ZnO}$ and $\mathrm{Fe}_{3} \mathrm{O}_{4}$, have attracted the interest of the research. The nanocrystalline $\mathrm{TiO}_{2}$ anatase $(6 \mathrm{~nm})$ with the BET specific surface area of $300 \mathrm{~m}^{2} \mathrm{~g}^{-1}$ and the direct band difference of $3.31 \mathrm{eV}$ were prepared sonochemically (Gonzalez-Reyes et al.) [84]. It was then subjected to heat treatment from 400 to $900{ }^{\circ} \mathrm{C}$ for 2 hours to produce the desired duck-rutile ratio. During the elaboration three stages were observed in the heattreated samples:

In the first stage, the anatase granules coagulate as a result of the temperature of the heat treatment, increasing the structural homogeneity and crystallinity, both phenomena producing a reduction of the specific surface. In the second stage the coexistence of two phases (anatase and rutile) are separated by a transition region, called an interface. In the last stage a process takes place in which the rutile nuclei evolve into a new form of equilibrium without the presence of the anatasa phase, minimizing the total energy of the surface and the border, by the diffusion of mass transport. In this last stage, the rutile phase has the only function of growth and densification.

To encapsulate $\mathrm{Fe}_{3} \mathrm{O}_{4}$ nanocrystals into fibers using sonic-chemical synthesis followed by a reflux procedure (Yang et al.) [46], a method was developed by adapting the use of tetraethylortosilicate, ammonia, $\mathrm{Cd}^{2+}$ and thiolglycolic acid to a synthesis.
Conducted by ultrasound, the $\mathrm{Fe}_{3} \mathrm{O}_{4}$ nanoparticles were coated with a thin shell. Ultrasound treatment plays an important role in preventing $\mathrm{Fe}_{3} \mathrm{O}_{4}$ agglomeration. The monodisperse $\mathrm{Fe}_{3} \mathrm{O}_{4}$ particles in the fibers showed a superparamagnetic behaviour. The $\mathrm{ZnO}, \mathrm{NiO}_{2}$ and $\mathrm{MnO}$ nanowires were successfully synthesized by the sonochemical method in solutions at room temperature. The reactants used are $\left(\mathrm{M}(\mathrm{Ac})_{2} 2 \mathrm{H}_{2} \mathrm{O}\right.$, sodium hydroxide $\mathrm{NaOH}$ and $\mathrm{H}_{2} \mathrm{O} / \mathrm{C}_{2} \mathrm{H}_{6} \mathrm{O}$ as carrier in polyethylene glycol matrix. Parameters $(\mathrm{NaOH}$ solution concentration, ultrasonic strength and sonication time) influenced the morphology of the nanostructures (Aslani and collaborators) [47].

Askarinejad and his colleagues investigated the epoxidation of styrene and cyclooctene with anhydrous tert-butyl hydroperoxide on prepared nanocatalysts $\left(\mathrm{Co}_{3} \mathrm{O}_{4}\right.$ and $\left.\mathrm{Mn}_{3} \mathrm{O}_{4}\right)$.

The results of the conversion activity were compared with conventional $\mathrm{Co}_{3} \mathrm{O}_{4}$ and $\mathrm{Mn}_{3} \mathrm{O}_{4}$. Under optimized reaction conditions, the nanocatalysts showed higher catalytic performance compared to conventional catalysts [48].

Titanium oxides $\left(\mathrm{TiO}_{2}\right)$ with honeycomb structures have been successfully replicated from a bio-template using a sonochemical method. The biotemplates of cedar wood type were irradiated under ultrasonic wave in $\mathrm{TiCl}_{4}$ solutions and then calcined at temperatures between 450 and $600{ }^{\circ} \mathrm{C}$ (Zhu et al.) [49]. Photocatalytic activities were evaluated by measuring the percentage of methylene blue degradation using UV-VIS spectroscopy. The calcination temperature has a strong effect on the photocatalytic activity.

$\mathrm{ZnO}$ nanoparticles were successfully developed by ball milling through solid-liquid reactions, assisted by ultrasonic wave. Ultrasonic waves have been found to be a key factor promoting the transformation from $\mathrm{Zn}(\mathrm{OH})_{2}$ to single-phase $\mathrm{ZnO}$ nanoparticles (Ding and Ting) [50].

$\mathrm{CuO}$ nanoparticles were sonically prepared from copper acetate and sodium hydroxide in the presence of polypropylene glycol and polyvinyl alcohol (Ranjbar-Karimi et al.) [51]. Variations of several parameters and their effects on the structural properties of nanoparticles (particle size and morphology) were investigated. A $0.05 \mathrm{M}$ solution of copper acetate in the presence of polypropylene glycol gave the best results. $\mathrm{Mn}_{3} \mathrm{O}_{4}$ nanoparticles were prepared using an isochemical method without requiring $\mathrm{pH}$ adjustment (Baykal et al.) $[52,56]$. The synthesized material was identified as a tetragonal. The magnetic evaluation revealed a blocking temperature of $313{ }^{\circ} \mathrm{C}$, above which the material behaves paramagnetically. The asymmetric coercive field is attributed to the interaction between ferromagnetic $\mathrm{Mn}_{3} \mathrm{O}_{4}$ and the antiferromagnetic $\mathrm{Mn}$ 
oxide at the nanoparticle surface. Binding of a semiessential amino acid, L-arginine, on the surface of the nanomagnetite, created a stable aqueous suspension using the step-by-step synthesis method (Theerdhala and co-workers) [53]. The initial concentration of the amino acid was shown to play an important role in particle sizing. It was found that lower concentrations of arginine favour the formation of elongated tubular structures, whereas at higher concentrations, elongated structures were less prominent and it was found that arginine is adsorbed on the magnetite surface. The formation of uniform $\alpha-\mathrm{Fe}_{2} \mathrm{O}_{3}$ nanoparticles has been reported and their magnetic properties have been investigated by Koo and his colleagues [54].
Sonochemical synthesis resulted in the formation of $\alpha-\mathrm{Fe}_{2} \mathrm{O}_{3}$ spherical nanoparticles with an average diameter of $60 \mathrm{~nm}$. $\mathrm{ZnO}$ microspheres were prepared by sound-chemical synthesis at room temperature using carbon spheres as a template (Xiaohua et al.). The diameter of the hollow spheres obtained is about $500 \mathrm{~nm}$, and the walls are composed of numerous nanocrystalline $\mathrm{ZnO}$ aggregates with diameters of $90 \mathrm{~nm}$. A growth mechanism has been proposed for the formation of $\mathrm{ZnO}$ microspheres, in which carbon spheres play a crucial role in the formation of hollow $\mathrm{ZnO}$ microspheres $[55,57,58]$.

The advantages and disadvantages of the sonochemical method are summarized in the following Table 7.

Table 7. Advantages and disadvantages of the sonochemical method

\begin{tabular}{|c|c|}
\hline Advantages & Disadvantages \\
\hline$\checkmark \quad$ improves reaction rate; & $\checkmark \quad$ extension of problems; \\
\hline $\begin{array}{c}\checkmark \quad \text { involves high energies and pressures in a } \\
\text { short time; }\end{array}$ & $\checkmark \quad$ inefficient energy; \\
\hline$\checkmark \quad$ no additives needed; & $\checkmark \quad$ low yield. \\
\hline$\checkmark \quad$ reduced number of reaction steps. & \\
\hline
\end{tabular}

\section{Conclusions}

There are two types of approaches to the synthesis of nanomaterials: top down and bottom-up. The "top down" synthesis, nanoparticles are obtained by reducing the size of macroscopic systems at nanometres. The "bottom-up" method is much more used for the elaboration of nanoparticles, because it allows to control their size. In order to elaborate the nanomaterials, the chemical methods allow the control of the reaction parameters so that particles of nanometric dimensions are obtained. In the literature there are studies on the advantages and disadvantages of chemical methods [56]. Some of these specific advantages and disadvantages consist of: sol-gel synthesis has many advantages for producing high quality materials with homogeneity and purity at lower temperatures than conventional methods, and as a disadvantage it has a long processing time, Pechini method has the advantage that it is widely used in the synthesis of dielectric, fluorescent and magnetic materials, superconductors and high temperature catalysts, as well as for the deposition of oxide films and coatings, and as a disadvantage the use of organic reagents that can be toxic. The microemulsion method allows the control of particle properties such as size, geometry, morphology, homogeneity and surface area. The disadvantage of the microemulsion method is the large amount of surfactants used. One of the advantages of the sonochemical method is that it involves high energies and pressures in a short time, and the disadvantage is the low efficiency.

\section{References}

[1]. Mittal A. K., Chisti Y., Banerjee U. C., Biotechnology Advances, 31 (2), p. 346-356, 2013.

[2]. Ebelmen J. J., Comptes rendus de l'Académie des Sciences 19, 398, (1844).

[3]. Ebelmen J., Annals of Chemistry and of Physics, 57, p. 319355, 1846.

[4]. Geffcken W., Berger E., Verfahren zur Änderung Reflexionsvermögens Optischer Gläser, Deutsches Reichs patent, 736 411, assigned to Jenaer Glaswerk Schott \& Gen, 1939.

[5]. Shek C. H., Lin G. M., Lai. Nanostruct Mater, 11(7), p. 831835, 1999.

[6]. Bruni S., Cariati F., Casu M., Lai A., Musinu A., Piccaluga

G., Solinas S., Nanostruct. Mater., 11 (5), p. 573, 1999.

[7]. Andrei Jitianu, J Solgel Sci Technol, 26, p. 483-488, 2003.

[8]. Mahshid S., Askari M., Sasani Ghamsari M., J. Mater. Process. Technol., 189, p. 296-300, 2007.

[9]. Gash A. E., Tillotson T. M., Satcher J. H., Poco J. F., Hrubesh L. W., Simpson R. L., Chem. Mater, 13(200), p. 9991007, 2001.

[10]. Tang N. J., Zhang W., Jiang H. Y., Wu X. L., Liu W., Du Y. W., J. Magn. Magn. Mater., 282, p. 92-95, 2004.

[11]. Shaker S., Zafarian S., Chakra C. S., Rao K. V., Int J Innov Res Sci Eng Technol, 2(7), p. 2969-2973, 2013.

[12]. Abolfazl Khodadadi, Majid Farahmandjou, Mojtaba Yaghoubi, Ali Reza Amani, J Am Ceram Soc, 16(2), p. 429-882, 2018.

[13]. Yanming Sun, Jung Hwa Seo, Christopher J. Takacs, Jason Seifter, Alan J. Heeger, Adv. Mater. Technol., 23, p. 16791683, 2011.

[14]. Tayseir M., Abd. Ellateif., Saikat. Mitra., J. of Adv in Nanomat, 2, 4, 2017.

[15]. Tai L. W., Lessing P., J. Mater. Res., vol. 7, p. 502-510, 1992. 


\section{THE ANNALS OF "DUNAREA DE JOS” UNIVERSITY OF GALATI FASCICLE IX. METALLURGY AND MATERIALS SCIENCE \\ No. 1 - 2020, ISSN 2668-4748; e-ISSN 2668-4756 \\ Article DOI: $\underline{\text { https://doi.org/10.35219/mms.2020.1.08 }}$}

[16]. Tai L. W., Lessing P. A., J. Mater. Res., vol. 7, p. 511-519, 1992.

[17]. Kakihana M., Yoshimura M., Bull. Chem. Soc. Jpn. vol. 72, p. 1427-1443, 1999.

[18]. Julian Eastoe Martin, J. Hollamby Laura Hudson. Adv Colloid Interfac, 128-130, 5-15, 2006.

[19]. Destrée C., George S., Champagne B., Guillaume M., Ghijsen J., Nagy J. B., Colloid Polym Sci, 286, p. 15-30, 2008.

[20]. Zhong-min Ou, Hiroshi Yao, Keisaku Kimura, J Photochem Photobiol A Chem, 189-1, p. 7-14, 2007.

[21]. Wanzhong Z., Xueliang Q., Jianguo C., Chem. Phys, 330(3), p. 495-500, 2006.

[22]. Hu A., Yao Z., Yu X., J. Appl. Polym. Sci, 2009.

[23]. Marie-Paule Pileni, Cr. Chim 6, 8-10, p. 965-978, 2003.

[24]. Pileni M. P., J. Phys. Chem. C, 17, p. 7476-7487, 2001.

[25]. M. P., J. Phys. Chem. C, 111, p. 9019-9038, 2007.

[26]. Pileni M. P., Acc. Chem. Res., 41, p. 1799-1809, 2008.

[27]. Lopez Quintela M. A., Tojo C., Blanco M. C., Garcia Rio

L., J. R. Curr. Opin. Colloid. Interf. Sci., 9, p. 264-278, 2004

[28]. Cushing B. L., Kolesnichenko V. L., C. J. O. Chem. Rev., 104, p. 3893-3946, 2004

[29]. Shervani Z., Ikushima Y., Hakuta Y., Kunieda H., K. Colloid. Surf. A: Physicochem. Eng. Asp., 289, p. 229-232, 2006.

[30]. Holmes J. D., Lyons D. M., K. J. Chem. Eur. J., 9, p. 21442150, 2003.

[31]. Boutonnet M., Kizling J., Stenius P., Colloid Surf., 5, p. 209-225, 1982

[32]. Boutonnet M., Kizling J., Stenius P., Maire G., Colloid. Surf., 5, p. 209-225, 1982.

[33]. Bandow S., Kimura K., Konno K., Kitahara A., Jpn. J. Appl. Phys., 26, p. 713-717, 1987.

[34]. Ayyup P., Multani M., Barma M., Palkar V. R., Vijayaraghavan R., J. Phys. C: Solid State Phys., 21, p. 22292245, 1988.

[35]. Hou M. J., Shah D. O., In: Attia, Y.A. (Ed.), Elsevier, Amsterdam, 443, 1988.

[36]. Lal M., Chhabara V., Ayyub P., Maitra M. A., J. Mater. Res., 13, p. 1249-1254, 1998.

[37]. Zhang D., Qi L., Ma J., Cheng H., J. Mater. Chem., 12, p. 3677-3680, 2002.

[38]. Maqsood Ahmad Malik, Mohammad Younus Wani, Mohd Ali Hashim, Arab J Chem, 5 (4), p. 397-417, 2012.
[39]. Komarneni S., Li Q., Stefansson K. M., Roy R., J. Mater. Res., 8, 12, p. 3176-3183, 1993.

[40]. ***, Chemical encyclopedia, vol. 1, Moscow: Sovetskaja enciklopedija, p. 567, 1988.

[41]. ***, Hydrothermal synthesis, Wikipedia, the free Encyclopedia.http://en.wikipedia.org/wiki/Hydrothermal_synthesis , 2009.

[42]. Meskin P. E., Ivanov V. K., Baranchikov A. E., Churagulov B. R., Tretyakov Yu. D., Ultrason. Sonochem, 13, p. 47-53, 2006.

[43]. Suslick K. S. Kirk-Othmer, Encyclopedia of Chemical Technology, Ed. J. Wiley \& Sons: New York, 26, p. 517-541, 1998. [44]. Hangxun Xu, Brad W. Zeiger, Kenneth S. Suslick, Chem Soc Rev, 2012.

[45]. Gonzalez J. R., Alcantara R., Nacimiento F., Tirado J. L., Electrochem. Acta, 56, p. 9808-9817, 2011.

[46]. Yang P., Zhang A. Y., Cheng X., Zhou G. J., Lue M. K., J. Colloids Int. Sci., 351, p. 77-82, 2010.

[47]. Aslani A., Bazmandegan-Shamili A., Kaviani K., Phys. B Condens. Matter, 405, p. 3972-3976, 2010.

[48]. Askarinejad A., Bagherzadeh M., Morsali A., Appl. Surf. Sci. 256, p. 6678-6682, 2010.

[49]. Zhu S. M., Zhang D., Chen Z. X., Zhou G., Jiang H. B., Li

J. L., J. Nanoparticle Res., 12, p. 2445-2456, 2010.

[50]. Ding C., Ting X. A., J. Am. Ceram. Soc., 93, p. 2675-2678, 2010.

[51]. Ranjbar-Karimi R., Bazmandegan-Shamili A., Aslani A., Kaviani K., Phys. B Condens. Matter., 405, p. 3096-3100, 2010

[52]. Baykal A., Kavas H., Durmus Z., Kazan S., Topkaya R., Toprak M. S., Cent. Eur. J. Chem., 8, p. 633-638, 2010.

[53]. Theerdhala S., Bahadur D., Vitta S., Perkas N., Zhong Z.

Y., Gedanken A., Ultrason. Sonochem., 17, p. 730-737, 2010.

[54]. Koo Y. S., Yun B. K., Jung J. H., J. Magn., 15, p. 21-24, 2010

[55]. Xiaohua J., Huiqing F., Faqiang Z., Lei Q., Ultrason. Sonochem., 17, p. 284-287, 2010.

[56]. Plăiașu A. G., Editura Universitatii din Pitesti, 2016.

[57]. Barca E. S., Plaiasu A. G., Abrudeanu M., Istrate B., Luca

D., Munteanu C., J. Optoelectron. Adv. M., 17, 9-10, p. 1522$1527,2015$.

[58]. Plăiașu A. G, Abrudeanu M., Dicu M., Monty C., J. Optoelectron. Adv. M., 16, 9-10, p. 1116-1112, 2014. 